determined using specific assays. Finally, the potential of 3NBA to alter the cellular metabolism was assessed by gas chromatography-mass spectrometry.

Result RT4 cells were capable of bioactivation of 3-NBA within $30 \mathrm{~min}$, whereas the main contributor for bioactivation of 3-NBA was $\mathrm{NAD}(\mathrm{P}) \mathrm{H}$ :quinone oxidoreductase (NQO1). Cytotoxicity assessment revealed an activation of adaptive mechanisms at low dosages, which diminished at higher doses.

The metabolomic analysis of the cells showed elevated levels of various antioxidants at low concentrations of 3-NBA. At higher exposure concentrations, it appeared that the cells reprogrammed their metabolism to maintain the pentose phosphate pathway (PPP) aiding in cell protection.

Discussion Starting from a relevant environmental dose of $0.0003 \mu \mathrm{M}$ up to $80 \mu \mathrm{M}$, we described the driving mechanism behind the different cellular states - in particular an activation of adaptive mechanisms at low dosages, which diminished at higher doses. The metabolomic data suggested that the PPP and the folate metabolism play a leading role in this transition. Moreover, there was evidence for an additional carbon flux into PPP via the gluconate metabolism to support the formation of NADPH, which in term is an important determinant of the defence system against oxidative stress.

\section{HEART RATE VARIABILITY IN SMELTER FURNACE WORKERS}

${ }^{1} \mathrm{MD}$ Bugge*, ${ }^{1} \mathrm{~B}$ Ulvestad*, ${ }^{1} \mathrm{~B}$ Berlinger*, ${ }^{1} \varnothing$ Skare*$^{*},{ }^{2} \mathrm{~K}$ Gjesdal*, ${ }^{1} \mathrm{DG}$ Ellingsen*. 'STAMI, National Institute of Occupational Health, Oslo, Norway; ${ }^{2}$ Oslo University Hospital, Oslo, Norway

\subsection{6/oemed-2018-ICOHabstracts.1182}

Introduction Exposure to fine particulate matter in urban air has been associated with increased risk of hospitalisation and death from cardiovascular diseases. One hypothesis suggests a direct influence of particles on the autonomic nervous system. Some studies have shown an association between particle exposure and reduced heart rate variability (HRV). Furnace workers in metal smelters are occupationally exposed to fine and ultrafine particles. The aim of this study was to examine the association between exposure to particulate matter in metal smelters and HRV.

Methods We examined 64 workers in three Norwegian metal smelters on a working day, and on a day off after at least two days since last exposure. On the working day, exposure to different particle size fractions was assessed by personal sampling, using respirable cyclones and five-stage Sioutas cascade impactors. The workers carried Holter monitors for 24 hours' heart rate registration during the working day and the day off. HRV indices were analysed by exposure for each hour of the day, using mixed model regression, adjusted for relevant covariates.

Results There were 58 male and 6 female workers. Their mean age was 34 years (range 19-64). The mean exposure to respirable particulate matter was $2.36 \mathrm{mg} / \mathrm{m}^{3}$, while $0.88 \mathrm{mg} /$ $\mathrm{m}^{3}$ was below $250 \mathrm{~nm}$. Standard deviation of normal-to-normal intervals (SDNN) was reduced during working hours on the working day relative to the day off, whereas in the afternoon and night hours there were no significant differences. Low frequency/high frequency $(\mathrm{LF} / \mathrm{HF})$ ratio was higher during working hours on the working day, but in the afternoon and evening hours the LF/HF ratio was significantly higher on the day off compared to the working day.
Conclusion HRV indices differ between working day and day off. Analyses are in progression, and further results on the effects of particle exposure will be presented.

\section{CONTRIBUTIONS OF DERMAL VS AIR EXPOSURE TO BIOMONITORING FOR SOLVENT EXPOSURE}

${ }^{1}$ Matteo Creta*, ${ }^{2}$ Horatiu Moldovan, ${ }^{3}$ Septimiu Voidazan, ${ }^{1,4}$ Lode Godderis, ${ }^{1}$ Radu Corneliu Duca, 'Jeroen Vanoirbeek. 'Environment and Health, University of Leuven (KU Leuven), Belgium; ${ }^{2}$ Occupational Medicine Department, University of Medicine and Pharmacy of Tirgu-Mures, Romania; ${ }^{3}$ Epidemiology Department, University of Medicine and Pharmacy of Tirgu-Mures, Romania; ${ }^{4} / d e w e$, External Service for Prevention and Protection at Work, Heverlee, Belgium

\subsection{6/oemed-2018-ICOHabstracts. 1183}

Introduction Dermal exposure assessment is becoming increasingly important in occupational settings, but its contribution to the overall body burden is not yet well-established. Therefore, we evaluated the contribution of dermal exposure to the total body burden as reflected by biomonitoring, by simultaneous quantitative assessment of dermal, and air exposure in combination with bio- monitoring, in workers exposed to solvent.

Methods Exposure to the volatile organic compounds, styrene, acetone and toluene on the skin was evaluated using activated charcoal cloth patches; inhalation exposure was measured using passive organic vapour monitors, and systemic exposure was assessed by quantification of mandelic acid, acetone and hyppuric acid in urine, as biomarkers for styrene, acetone and toluene, respectively. Exposure was measured in 40 workers performing different tasks: hydraulic press (HP) workers, sheet moulding composite (SMC) workers, mechanics and office workers in a thermoplastic panels factory.

Results For styrene, the dermal exposure levels found were higher for HP workers $\left(1532 \pm 450 \mu \mathrm{g} / \mathrm{cm}^{2}\right)$ than for the other workers (e.g. SMC 179 \pm 50 ). Inhalation exposure levels for $\mathrm{HP}$ and SMC workers were similar $\left(58 \pm 11 \mathrm{mg} / \mathrm{m}^{3}\right.$ and $60 \pm 8$ $\mathrm{mg} / \mathrm{m}^{3}$, about $70 \% \mathrm{TLV}$ ), but urinary concentrations of mandelic acid were higher for HP $(549 \pm 85 \mu \mathrm{g} / \mathrm{mL})$ then SMC $(331 \pm 21 \mu \mathrm{g} / \mathrm{mL})$ workers. In addition, a good correlation between dermal, air and urinary levels of acetone was found. Unlike for styrene and acetone, toluene levels in air were less than $1 \%$ TLV, regardless of the tasks performed by the workers. No relevant dermal or inhalation exposure was found for mechanics and office workers.

Discussion This study shows that for solvents, high dermal exposure substantially contributed to the increased concentrations of urinary metabolites. Therefore, the contribution of dermal exposure to the overall body burden is as important as the respiratory exposure, especially for less-volatile solvents, such as styrene.

\section{ORGANOPHOSPHATES IN THE WORKPLACE: A 20-YEAR PROSPECTIVE STUDY}

${ }^{1} \mathrm{~N}$ Loio-Marques, ${ }^{2} \mathrm{M}$ Felgueiras, ${ }^{3} \mathrm{~L}$ Guilhermino, ${ }^{4} \mathrm{C}$ Valls-Llobet. ${ }^{1}$ Occupational Medicine Resident, Centro Hospitalar Porto, Porto, Portugal; ${ }^{2}$ Clinical Pathology Resident, Centro Hospitalar Cova da Beira, Covilhã, Portugal; ${ }^{3}$ PhD Biology, Instituto Ciências Abel Salazar, Porto, Portugal; ${ }^{4}$ Endocrinologist, Centre d'Atenció i Programes Sanitaris, Barcelona, España

\subsection{6/oemed-2018-ICOHabstracts. 1184}


Introduction The organophosphates (OPs) are a group of insecticides that have been widely used worldwide for the past 50 years. It is estimated that 3,000,000 people are exposed to OPs yearly, with the associated death rate being 3,00,000 deaths/year. OPs are cholinergic inhibitors and their toxicity is possible through acute or chronic exposure, with severe consequences for different organs and systems. The main objective of this study was to identify signs and symptoms of exposure to OPs on women with chronic exposure.

Methods A prospective study (1994-2014) followed up 43 women exposed to OPs, and evaluated signs and symptoms described as being associated to OPs exposure, as well as analytical parameters associated to asthenia and cellular protection, namely pyruvate (PA) and lactate (LA).

Results During the first appointment, 98\% of the women had asthenia. Among the evaluated signs and symptoms, musculoskeletal injuries (78\%) and menstrual cycle changes (36\%) occurred with the highest frequency. Slightly less frequent were the changes observed in the peripherical nervous system (11\%). Regarding the evaluated biochemical parameters, women generally showed a decrease in ferritin and an increase in TSH. Throughout the study a progressive drop in AChE was observed. In $64 \%$ and $92 \%$ of the women a change in PA and LA values respectively was observed.

Discussion The results suggest that prolonged exposure to OPs can chronically affect different human organism systems, namely parameters related to mitochondrial dysfunction

\section{DERMAL EXPOSURE TO DIISOCYANATES: DEVELOPMENT AND VALIDATION OF AN ANALYTICAL METHOD FOR ACCURATELY ASSESSMENT OF VERY LOW LEVELS OF EXPOSURE}

${ }^{1}$ Radu-Corneliu Duca* ${ }^{1}$ Matteo Creta, ${ }^{1}$ Katrien Poes, 1,2 lode Goddeis, ${ }^{1} J$ Jeroen Vanoirbeek. 'Environment and Health, Department of Public Health and Primary Care, University of Leuven, Leuven, Belgium; ${ }^{2}$ External Service for Prevention and Protection at Work, IDEWE, Haasrode, Belgium

\subsection{6/oemed-2018-ICOHabstracts. 1185}

Introduction Dermal exposure to sensitizers such as diisocyanate have been described to promote the development of asthma in later stages when respiratory occupational exposure occurs. Therefore, we developed a reliable, sensitive and validated methodology based on dermal patches to assess skin exposure to diisocyanates.

Methods An UPLC-Unispray-MS/MS method was established and validated in order to reach very low levels of detection. Custom-made dermal patches were developed in order to allow optimal sampling of diisocyanates. Their sampling capability was evaluated in a controlled environment test-chamber were patches were exposed to increasing concentrations of diisocyanates.

Result The UPLC-MS/MS method using a Unispray ionisation source, based on supercritical fluids ionisation and Coanda effect, allowed reaching very low levels of detection $(\operatorname{LoD}=1$ $\mathrm{pg} / \mathrm{mL}$ ) for all the targeted compounds (i.e. 4,4-MDI, 2,4MDI, 2,6-TDI, 2,4-TDI, 1,6-HDI, and IPDI). Due to the high sensitivity of the analytical method, very low levels of diisocyanates (i.e. $25 \mathrm{pg} / \mathrm{patch}$ ) are detected on the custom-made dermal patches. Furthermore, the patches allowed the sampling of a broad range of concentration levels (from $5 \mathrm{pg} / \mathrm{cm}^{2}$ to $5 \mathrm{ng} / \mathrm{cm}^{2}$ ), which have been correlated with the air levels from the controlled environment chamber-test.
Discussion We succeeded to develop a method to assess dermal exposure to diisocyanates. Field studies are now necessary to further evaluate the suitability of the custom-made patches, as well as to relate low levels of exposure and potential health outcomes.

\section{Primary Care and Work}

\section{SCALING UP WORKERS' HEALTH COVERAGE THROUGH PRIMARY HEALTH CARE}

${ }^{1}$ Garth Manning, ${ }^{2}$ Frank van Dijk, ${ }^{2}$ Peter Buijs. 'Chief Executive Officer, World Organisation of Family Doctors (WONCA); Bangkok, Thailand; 'Learning and Developing Occupational Health (LDOH) foundation, The Netherlands

\subsection{6/oemed-2018-ICOHabstracts. 1186}

Aim To explore ways of upskilling primary health care to offer essential occupational health to a broader population; some country examples.

Presenters: ${ }^{1}$ Prof Jukka Takala, ${ }^{2}$ Dr Ramnik Parekh, ${ }^{3}$ Dr Orrapan Untimanon, ${ }^{4}$ Dr Hanifa M Denny, ${ }^{5}$ Dr Ezequiel Lopez, ${ }^{6} \mathrm{Dr}$ Muzimkhulu Zungu, ${ }^{7}$ Dr Ahmet Özlüh, ${ }^{8}$ Dr Paul Smits

${ }^{1}$ President of International Commission on Occupational Health (ICOH); Senior Consultant, Ministry of Manpower Services Centre, Singapore

${ }^{2}$ Chair- Mission BOHS: Indian Association of Occupational Health (IAOH), Mumbai, India

${ }^{3}$ Bureau of Occupational and Environmental Diseases, Department of Disease Control, Ministry of Public Health, Thailand

${ }^{4}$ Diponegoro University, Semarang, Indonesia

${ }^{5}$ Clinica Belgrano Family Medicine and Occupational Health Department, Quilmes, Argentina

${ }^{6}$ National Institute for Occupational Health School of Health Systems and Public Health, University of Pretoria

${ }^{7}$ Republic of Turkey Ministry of Health, General Directorate of Public Health, Ankara, Turkey

${ }^{8}$ Centre for evidence-based education, Academic Medical Centre (AMC), Amsterdam, The Netherlands

\section{1a GLOBAL BACKGROUND OF INSUFFICIENT COVERAGE BY OCCUPATIONAL HEALTH SERVICES: WHAT CAN WE DO TO SUPPORT PREVENTION AND CARE}

Jukka Takala. Senior Consultant, Ministry of Manpower Services Centre, Singapore

\subsection{6/oemed-2018-ICOHabstracts. 1187}

Background According to latest estimates by ILO 2.8 million men and women die every year caused by problems at work. Health disorders cause 2.4 million deaths. Costs are $3.9 \%$ of the global GDP or 3 trillion (million millions) USD. Problems include: poor legal and enforcement coverage, poor or no workers' compensation systems, poor or no occupational health services - some $15 \%$ or less of the global workforce is covered. According to WHO 93\% of global health resources go for treatment and 7\% for prevention. Lack of knowledge, policies, systems and resources is evident.

Methods and processes A number of solutions and good practices have been identified to be useful and successful, although largely in developed countries. Simple methods to increase coverages and enhance services are needed. The ILO 